\title{
Do women seeking care from obstetrician-gynaecologists prefer to see a female or a male doctor?
}

\author{
Adinarayana Makam • \\ Channamallikarjuna Swamy Mallappa Saroja • \\ Gareth Edwards
}

Received: 15 June 2009 / Accepted: 26 July 2009 / Published online: 11 August 2009

(C) Springer-Verlag 2009

\begin{abstract}
Purpose To examine whether women seeking care from obstetrician-gynaecologists prefer to see a female or a male doctor or have no preference.

Methods Five hundred consecutive women attending gynaecology and antenatal clinics were asked to complete a survey questionnaire containing 12 items requiring opinion on whether they want to be seen by a female or male obstetrician-gynaecologist or have no preference. It also contained questions regarding their reasons for the stated preference.

Results Of the consecutive 500 patients that were given the questionnaire, 435 responded ( $87 \%$ response rate). Two hundred and twenty-five patients had no preference, 194 patients preferred female obstetrician-gynaecologist and 16 patients preferred male obstetrician-gynaecologist. The reasons stated by women who preferred to see a female doctor were as follows: religious beliefs- $5 \%$, understands problems better- $48 \%$, unspecified reasons- $6 \%$, issues of personal modesty-41\%. All 16 women who preferred to see a male doctor stated the reason as 'understands problems better' (100\%).

Conclusions The majority of women expressed no preference to either gender of their obstetrician and gynaecologists, but significant proportion of the remainder would prefer to see a female doctor when given the choice. Although women gave a variety of subjective reasons for this, demographically it appears that women who are less educated with lower income and being non-white are more likely to prefer to see a female doctor.
\end{abstract}

A. Makam · C. S. Mallappa Saroja $(\bowtie) \cdot$ G. Edwards

Nevill Hall Hospital, Abergavenny, UK

e-mail: drmscswamy@yahoo.com
Keywords Gender preference ·

Obstetrician-gynaecologist $\cdot$ Medical student

\section{Introduction}

The number of UK graduates considering obstetrics and gynaecology as career is steadily falling [10]. Amongst new male medical graduates, only one in 500 choose to specialisation in obstetrics and gynaecology [5]. Ninety percent of UK registrars have done their training outside the United Kingdom [20]. Why not allow only women into obstetrics and gynaecology? Primarily because that would be akin to telling all geriatricians should be elderly [19]. And also, patients may want to see a male doctor or have no preference at all as to their doctor's sex (some female patients find it less embarrassing to expose themselves to a man than to another woman [8]. Internal examinations on patients and ethics have long been debated [1]. Ethically, patients should be examined with the sole aim of diagnosing or ruling out certain condition, and it is unacceptable to use a patient for personal gain. However, it can also be argued conversely, that is, training medical students allows more doctors, so patients should be examined bearing in mind the greatest good for the greatest number of people. Large number of patients do refuse dashing young male students from observing their most intimate areas and the invasive techniques that doctors apply to them, solely because the student is male [6]. It is unwise and unfair to deny male gynaecologists an ability to practice what they do best. As a result of equal opportunities legislation, medical schools and the Royal College of Obstetricians and Gynaecologists need clearer guidelines to prevent discrimination against men. We examined the preference of the patients with respect to the sex of the obstetrician and gynaecologist in a hospital setting in UK. 


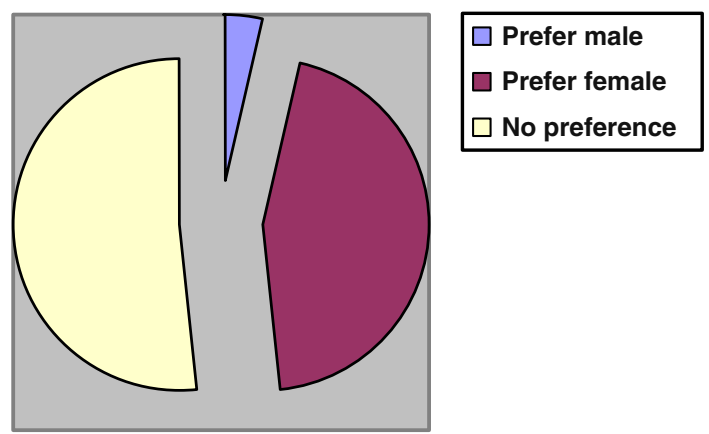

Fig. 1 Preference of the patients with respect to the sex of the obstetrician and gynaecologist

\section{Objective}

To examine whether women seeking care from obstetrician-gynaecologists prefer to see a female or a male doctor or have no preference.

\section{Materials and method}

Women attending antenatal and gynaecology outpatient departments at the Royal Gwent Hospital, Newport, UK, were asked to participate in the survey. The questionnaire consisted of 12 items, given out by clinic staff, to be completed in the waiting area before seeing the doctor and the patients were requested to drop the completed questionnaire into a sealed box kept at the reception to maintain confidentiality.

\section{Results}

The study sample comprised 435 (87\% response rate) of 500 consecutive patients attending the antenatal and gynaecology outpatient departments. Given the choice 225 patients had no preference, 194 patients' preferred female obstetrician-gynaecologist and 16 patients preferred male obstetrician-gynaecologist (Fig. 1). The reasons stated by women who preferred to see a female doctor were as follows: religious beliefs- $5 \%$, understands problems better$48 \%$, unspecified reasons-6\%, issues of personal modesty- $41 \%$ (Fig. 2). All 16 women who preferred to see a male doctor stated the reason as 'understands problems better' $(100 \%)$.

For the purpose of data analysis, the study population was divided into two groups and compared with regard to their demographic characteristics (Table 1). There was statistically significant difference between the two groups in age, ethnic origin, education, annual income and parity.

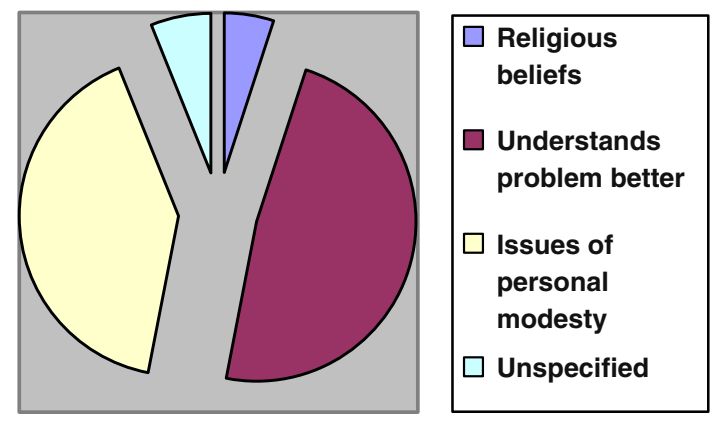

Fig. 2 The reasons stated by women who preferred to see a female doctor

Table 1 The demographic characteristics of the study population

\begin{tabular}{|c|c|c|c|}
\hline Variable & $\begin{array}{l}\text { Prefer female } \\
N=194\end{array}$ & $\begin{array}{l}\text { No preference } \\
N=225\end{array}$ & $P$ value \\
\hline \multicolumn{4}{|l|}{ Age } \\
\hline$<20$ & 19 & 36 & 0.0015 \\
\hline $21-30$ & 37 & 45 & 0.20 \\
\hline $31-40$ & 76 & 40 & $<0.0001$ \\
\hline $41-50$ & 40 & 66 & 0.006 \\
\hline$>50$ & 22 & 38 & 0.0052 \\
\hline \multicolumn{4}{|l|}{ Ethnicity } \\
\hline White & 152 & 211 & $<0.0001$ \\
\hline Asian & 39 & 14 & $<0.0001$ \\
\hline Mixed & 1 & 0 & \\
\hline Black & 0 & 1 & \\
\hline Others & 1 & 0 & \\
\hline \multicolumn{4}{|l|}{ Education } \\
\hline$<\mathrm{GCSE}$ & 37 & 27 & 0.07 \\
\hline GCSE & 33 & 41 & 0.23 \\
\hline A level & 66 & 35 & $<0.0001$ \\
\hline Diploma & 31 & 58 & 0.0001 \\
\hline Degree & 27 & 64 & $<0.0001$ \\
\hline \multicolumn{4}{|c|}{ Annual income } \\
\hline$<10,000$ & 7 & 18 & 0.0031 \\
\hline $10-40,000$ & 151 & 122 & 0.0221 \\
\hline$>40,000$ & 36 & 85 & 0.0001 \\
\hline \multicolumn{4}{|l|}{ Parity } \\
\hline Nulliparous & 45 & 43 & 0.79 \\
\hline Parous & 149 & 182 & 0.0112 \\
\hline
\end{tabular}

\section{Discussion}

Both male and female medical students have expressed their uneasiness about what has been apparent as an antimale environment in obstetrics and gynaecology [16]. It has been stated that this idea of not being welcome in the specialty is one of the main reason for male medical students not taking up obstetrics and gynaecology as career [9]. 
A study by Haivas [5] showed that a large number of incidents of discrimination towards medical students were in obstetrics and gynaecology and a overwhelming majority of these reports included discrimination towards men.

Part of the reluctance of male students refusing to take up obstetrics and gynaecology as a career has been stated as difference in experience and performance [7]. Significant number of male students anecdotally report increasing numbers of women refusing to have male students involved in their care, often reflecting cultural issues.

A study carried out at King's College School of Medicine even suggested that students felt that some medical practices were incompatible with some religious beliefs [11]. This indicates that the differences between different cultures and their values may ultimately affect students' choice.

Our ability as human beings to empathise and support one another does not support the suggestion that men lack female organs and hence cannot relate to disorders of those organs ignores. This bypasses the fact that those men can still effectively treat women, even though they will never be able to experience the pain or discomfort of childbirth. Most female medical students have not experienced pregnancy either [18].

A male gynaecologist sexually assaults a patient in the film The Hand That Rocks the Cradle. Male gynaecologists were depicted discussing "freaky fannies" in the television series Bodies. This bad publicity for the specialty discourages male students from choosing obstetrics and gynaecology as a career.

One of the many myths is that obstetrics and gynaecology is perceived as dominated by women. But similarly surgery is perceived as dominated by men. One study questioned established female surgeons about their career choice and concluded that they were far more positive about the job and not too concerned about possible bias towards their male colleagues [17].

In a study by Fogarty et al., a total of 1,128 graduates were asked over a 10-year period as to what factors made the obstetrics and gynaecology appealing or unappealing [3]. The perception that doctors were able to get to know their patients on an individual basis and hence allow empathy to develop and continuity of patient care scored highly. Associated high workload was acknowledged and it was perceived less negatively than surgery [3, 15]. Therefore, other factors, such as the professional relationships built between the doctor and patient, are highly influential, and their significance as a motivational factor should never be underestimated.

What can be done to motivate the students and eradicate the misconceptions? It should be stressed that it is possible to succeed regardless of gender. Sex discrimination in medical training needs to be tackled to achieve this.
The inadequate practical training in obstetrics and gynaecology that many male medical students receive because of refused consent from patients and relatives requires that patients and relatives appreciate the importance of education to all medical students, male and female, if they are to become effective safe and competent doctors.

A career in a specialty that students consider will result in a poor work-life balance is unlikely to be pursued later on $[4,21]$. To address this, the positive aspects of these specialties need to be promoted, such as the highly valued working relationships with patients in obstetrics and gynaecology. A long-term review of working conditions, including effective implementation of measures, such as the European Working Time Directive, is needed [14].

Guy's, King's, and St Thomas' medical school makes use of gynaecology teaching associates [2], who allow students to perform bimanual and pelvic examinations on expert patients, the emphasis being on communication skills as well as the practical side. Another technique is to attend antenatal clinics regularly and to take part in antenatal ward rounds. When women come to the delivery suite and see a familiar face it helps ease the tension they might feel during labour. As examining the abdomen of a pregnant woman does not usually pose a problem, you have already made physical contact with the patient. Midwives hold the key in obtaining obstetric consent. Often the patients and the partners are happy once they realise you are there to help them in their birthing experience, as well as learn. Perhaps, exploring issues of consent and specific training for medical students should be given more attention in the midwifery curriculum. There has been a significant change of attitudes towards male midwives [13]. With many fathers postulating the idea that men can communicate the process to them better and help fathers to get more involved in labour might encourage more male midwives [20].

There are innumerable male obstetricians and gynaecologists who are very dextrous, excellent communicators and as a result make very good gynaecologists. There are many skills required, and not everyone has the same skills-male or female. Empathy is one of them. It is very important to be able to put yourself in a patient's place. But you do not have to be of the same sex to empathise. Numerous advances for the benefit of the women have been made by men. We would not understand ultrasound now if it were not for the work of Professor Ian Donald. Patrick Steptoe made the link between laparoscopy and infertility. In general, history will show that men have been more innovative than women in the field of gynaecology and obstetrics. However, this is mostly because of the fact that they lived in a time when only few women worked as medical doctors. People who have taken up gynaecology $-80 \%$ of them are men - have done so because they have a particular 
aptitude for and empathy with that specialty. It would be unwise and unfair to deny them the ability to practise what they do best. Furthermore, male gynaecologists and obstetricians have an important role as medical advisers with regard to fathers and male partners being encouraged to become more involved in child care and contraception.

An equal distribution of male and female obstetrics and gynaecologic providers is well justified. The sex of the physician is of minor importance to his or her patients when compared with these other characteristics. Instead of promoting a specific gender as more qualified or unqualified for certain medical specialties, colleges and schools of medicine should fully support any candidates who exhibit the personal and professional qualities that are most important to patients. The continued encouragement and active recruitment of interested, motivated, and qualified men who are called to enter the practice of obstetrics and gynaecology will result in an optimal balance, and an equal distribution of men and women in this specialty field.

The mix of medicine and surgery and the opportunity to make a substantial difference to someone's life is what motivates a doctor to undertake career in obstetrics and gynaecology. In addition, there is also added bonus of dealing with endocrinology, paediatrics amongst others, thereby covering a wide range of skills and knowledge. This obvious plethora of opportunities should not be confined to medical students of one sex, and moreover, female patients should be made more aware of equal rights for doctors as well as patients, and the need for training and progression.

The results of a study by Johnson et al. in Canada, however, demonstrate that many patients who prefer that their obstetrician-gynaecologists are women actually receive their obstetric and gynaecologic care from male providers [8]. According to the results of this survey, patients desire that the specialty be composed of well-qualified physicians, whether male or female.

Continuing to fail to recruit men to obstetrics and gynaecology will halve the pool of potential recruits while, allowing for career breaks, it will increase the number required. Additionally, negative undergraduate experiences may discourage men from involvement in contraception, well woman screening, and gynaecological problems in family practice. Excluding men from vital aspects of reproduction is essentially unwise, the lack of adequate male role models is already widely cited as a problem afflicting society as a whole.

\section{Conclusion}

The most important consideration for female patients obviously is to receive a professional and competent service $[8,12]$. The majority of women expressed no preference to either gender of their obstetrician and gynaecologists, but significant proportion of the remainder would prefer to see a female doctor given the choice. Although women gave a variety of subjective reasons for this, demographically it appears that women who are less educated with lower income and being non-white are more likely to prefer to see a female doctor.

The questions in the minds of bright young male and female doctors of new generation should be in the form of what virtues of a doctor do our patients appreciate most and not whether there will be a role for men in the specialty of obstetrics and gynaecology. They should be trying to find out what are the various skills that they need to acquire to become the best obstetricians and gynaecologists for women in the future. The fact that there will be a small percentage of women with a definite gender bias should not deter men and women from taking up this dynamic specialty. The results and findings of this study are of great value for men in medical colleges who might otherwise be considering various other specialties for fear of discrimination or lack of job opportunities in obstetrics and gynaecology.

Each student interprets advantages and disadvantages of various specialties in his own way. Despite various reasons that motivate medical students towards or away from various specialties, it is the student's interpretation of the various factors that will decide their future career.

Conflict of interest statement None.

\section{References}

1. Coldicott Y, Pope C, Roberts C (2003) The ethics of intimate examination-teaching tomorrow's doctors. Br Med J 326:97-101

2. Cowdrey L (2004) Gynaecological teaching associates. Stud Br Med J 12:468

3. Fogarty CA, Bonebrake RG, Fleming AD, Haynatzki G (2003) Obstetrics and gynaecology to be or not to be? Factors influencing ones decision. Am J Obstet Gynaecol 189(3):652-654

4. Gelfand DV, Podnos YD, Wilson SE, Cooke J, Williams RA (2002) Choosing general surgery: insights into career choice of current medical students. Arch Surg 137(8):941-945

5. Haivas I (2005) Sexual discrimination and harassment affects career choices. Stud Br Med J 13:221-264

6. Hamilton AJ (2006) "GAMMS": Go away, male medical student. Stud Br Med J 14:89-132

7. Higham J, Steer PJ (2004) Gender gap in undergraduate experience and performance in obstetrics and gynaecology: analysis of clinical experience logs. Br Med J 328(7432):142-143

8. Johnson AM, Schnatz PF, Kelsey AM, Ohannessian CM (2005) Do women prefer care from female or male obstetrician-gynecologists? A study of patient gender preference. J Am Osteopath Assoc 105(8):369-379

9. Lambert TW, Davidson JM, Evans J, Goldacre MJ (2003) Doctor's reasons for rejecting initial choices of specialties as longterm careers. Med Educ 37:312-318 
10. Lambert TW, Goldacre MJ, Turner G (2003) Career choices of United Kingdom medical graduates of 1999 and 2000: questionnaire surveys. Br Med J 326:194-195

11. Lempp H, Seale C (2006) Medical students' perceptions in relation to ethnicity and gender: a qualitative study. BMC Med Educ 6:17

12. Lund JD, Rohrer JE, Goldfarb S (2005) Patient gender preferences in a large military teaching hospital. Obstet Gynecol 105(4):747750

13. More W. Birthday boys. http://www.guardian.co.uk/Archive/Article/0,4273,4038418,00.html

14. Morris-Stiff GJ, Sarasin S, Edwards P, Lewis WG, Lewis MH (2005) The European working time directive: one for all and all for one? Surgery 137(3):293-297

15. Newton DA, Grayson MS, Thompson LF (2005) The variable influence of lifestyle and income on medical students? Career specialty choices: data from two U.S. medical schools, 1998-2004. Acad Med J Assoc Am Med Coll 80(9):809-814

16. Nora LM, McLaughlin MA, Fosson SE, Stratton TD, MurphySpencer A, Fincher RM, German DC, Seiden D, Witzke DB (2002) Gender discrimination and sexual harassment in medical education: perspectives gained by a 14-school study. Acad Med J Assoc Am Med Coll 77:1226-1234

17. Park J, Minor S, Taylor RA, Vikis E, Poenaru D (2005) Why are women deterred from general surgery training? Am J Surg 190(1):141-146

18. Pearse WH, Haffner WH, Primack A (2001) Effect of gender on the obstetric-gynecologic work force. Obstet Gynecol 97:794797

19. Pegler J (2004) Obstetrics and gynaecology—gender gap-what about geriatrics and psychiatry? [Electronic response to Jenny Higham and Philip J Steer, Gender gap in undergraduate experience and performance in obstetrics and gynaecology: analysis of clinical experience logs.] BMJ. http://www.bmj.bmjjournals.com/ cgi/eletters/328/7432/142\#47704

20. Royal College of Obstetricians and Gynaecologists (2006) A career in obstetrics and gynaecology. RCOG, London

21. Schwartz RW, Jarecky RK, Strodel WE, Haley JV, Young B, Griffen WO Jr (1989) Controllable lifestyle: a new factor in career choice by medical students. Acad Med J Assoc Am Med Coll 64(10):606-609 